\title{
NILAI PENDIDIKAN NOVEL SRI RINJANI KARYA EVA NOURMA DAN RELEVANSINYA DALAM PEMBELAJARAN SASTRA
}

\author{
Alpan Ahmadi \\ alpansori90@gmail.com \\ Program Studi Pendidikan Bahasa Indonesia, Institut Pendidikan Nusantara Global, \\ Indonesia, 83511
}

\begin{abstract}
Abstrak. Karya sastra merupakan sebuah cermin realitas kehidupan yang digambarkan pengarang dengan memanfaatkan imajinasinya. Penelitian ini bertujuan untuk 1) mendeskripsikan nilai pendidikan dalam novel Sri Rinjani karya Eva Nourma; dan 2) mendeskripsikan relevansi novel Sri Rinjani karya Eva Nourma dalam pembelajaran sastra. Penelitian ini merupakan penelitian deskriptif kualitatif dengan metode analisis isi. Hasil penelitian ini menunjukan bahwa di dalam novel Sri Rinjani karya Eva Nourma terdapat nilai-nilai pendidikan, yaitu nilai pendidikan agama, sosial, dan adat atau budaya. Novel Sri Rinjani karya Eva Nourma ini juga relevan digunakan sebagai penunjang pembelajaran sastra di sekolah.
\end{abstract}

Kata Kunci: Nilai Pendidikan, Novel, Pembelajaran

\section{PENDAHULUAN}

Karya sastra sebagai sebuah cermin realitas kehidupan yang digambarkan oleh pengarang dengan memanfaatkan imajinasinya tidak pernah lahir dari kekosongan nilai yang terjadi dalam siklus kehidupan masyarakat. Cerita yang disampaikan pengarang dalam sebuah karya sastra merupakan kritik terhadap nilai, sosial, budaya, agama, dan pendidikan.Wllek dan Warren berpandangan bahwa acuan sebuah karya sastra bukanlah dunia nyata, melainkan dunia fiksi (2014: 12).

Fenomena-fenomena yang diangkat oleh pengarang dalam sebuah karya sastra hampir mencakup segala aspek kehidupan yang dialami oleh masyarakat. Ramuan antara realitas kehidupan dengan kejadian di tengah masyarakat dengan daya imajinasi pengarang menghasilkan rentetan cerita kehidupan yang terlihat nyata meskipun unsur fiktif yang dibubuhkan pengarang terkadang berimbang namun juga terkadang berlebihan dari kehidupan nyata yang dilukiskan dalam sebuah karya sastra. Namun, pemilihan unsur fiktif yang dapat diterima akal dalam sebuah sastra memiliki nilai yang tinggi sebagai teladan maupun refleksi kehidupan.

Novel sebagai karya fiksi menawarkan sebuah dunia. Dunia yang dalam novel berisi model kehidupan yang diidealkan, dunia imajinatif yang dibangun melalui berbagai unsure intrinsiknya seperti peristiwa, plot, tokoh (penokohan), latar, sudut pandang, dan lain-lain yang kesemuanya juga bersifat imajinatif (Nurgiyantoro, 2010: 4).Dewasa ini novel banyak dinikmati oleh hampir semua kalangan masyarakat terutama generasi muda. Hal itu dikarenakan novel memuat tema-tema yang dekat dengan kehidupan masyarakat pembaca pada umumnya, selain unsur-unsur intrinsic dalam novel juga terdapat unsur ekstrinsik yang saling mendukung sehingga menciptakan cerita yang padu dan utuh.

Novel Sri Rinjani karya Eva Nourma mengemukakan dan menggambarkan kehidupan social budaya masyarakat pesisir SasakLombok. Dalam novel Sri Rinjani karya Eva Nourma digambarkan kondisimasyarakat Lombok yakni Desa Selayar dan Perigi yang hidup dalam kemiskinan dan lemahnya pendidikan. Desa Selayar dan Perigi merupakan salah satu daerah terpencil di Pulau Lombok, yakni di Kabupaten Lombok Timur.

Pendekatan Sosiologi sastra merupakan ilmu dalam kajian sastra yang mempelajari sastra dari segi sosial dan budaya pengarang, pembaca, dan teks sastra. Hal itu ditegaskan oleh Albert Memmi (dalam Rien T. Segers, 2000: 70) yang menyatakan sosiologi sastra mempunyai tiga kemungkingan penelitian yang menitikberatkan perhatian pada pengarang, teks sastra, dan masyarakat pembaca. Novel Sri 
Rinjani karya Eva Nourma yang dominan mengangkat sisi kehidupan social budaya masyarakat pesisir Sasak-Lombok yang merupakan daerah tempat pengarang bermasyarakat dan novel ini ditulis untuk dinikmati oleh masyarakat Lombok dianilisis dengan menggunakan pendekatan sosiologi sastra yang memang selaras dan tepat untuk mengupas dengan tuntas isi dari novel tersebut.

\section{METODE PENELITIAN}

Penelitian ini merupakan penelitian desktiptif kualitatif. Peneliti dalam penelitian ini mencatat dan menganalisis novel Sri Rinjani karya Eva Nourma serta melakukan wawancara dengan penulis yaitu Eva Nourma. Novel ini dikaji menggunakan metode yang digunakan dalam penelitian ini adalah analisis isi (content analysis) berdasarkan rumusan masalah yang telah dipaparkan sebelumnya. Weber menyatakan bahwa Content analysis merupakan suatu bentuk teknik penelitian yang memanfaatkan seperangkat prosedur untuk menaruh simpulan yang sahih dari sebuah buku atau dokumen (dalam Moleong, 2008: 168).

Metode tersebut digunakan untuk menelaah isi dari suatu dokumen. Dokumen dalam penelitian ini adalah novel Sri Rinjani karya Eva Nourma. Adapun hal-hal yang dideskripsikan dalam penelitian ini, yaitu mengenai aspek budaya masyarakat Sasak Lombok dan nilai peduli sosial yang terdapat dalam novel Sri Rinjani karya Eva Nourma.

Adapun untuk anaisis data menggunakan model analisis interaktif yang melibatkan pengumpulan data, reduksi data, penyajian data, dan penarikan simpulan. Untuk lebih jelasnya berikut gambar model interaktif oleh Miles dan Huberman (dalam Sugiono, 2012: 338).

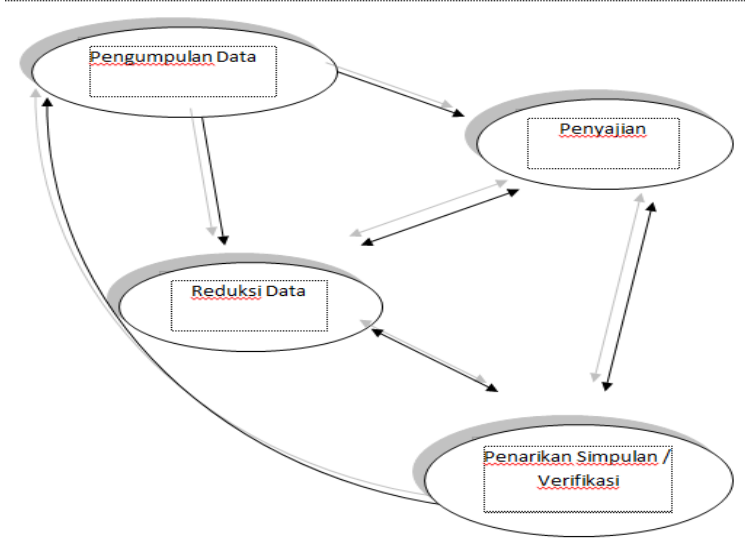

\section{HASIL PENELITIAN DAN PEMBAHASAN} 1. Nilai Penddikan dalam Novel Sri Rinjani Karya Eva Nourma.

\section{a. Nilai Pendidikan Agama}

Nilai pendidikan berkaitan tentang hubungan manusia dengan Sang Pencipta. Segala sesuatu yang terjadi di jagat raya dan peristiwa-peristiwa yang terjadi telah diatur dengan sangat rapi oleh Allah Sang Maha Pengatur. Nilai pendidikan agama dalam karya sastra merupakan unsur-unsur yang melatarbelakangi nilai keagamaan sebagai cermin tokoh ataupun pengarang dalam cerita. Sikap dan perilaku yang taat dalam menjalankan ajaran agama ditunjukkan oleh tokoh-tokoh dan masyarakat, seperti mendirikan sholat. Hal itu dapat dilihat pada kutipan berikut.

Paman Badrun mengisyaratkan untuk kami sholat magrib secara berjamaah terlebihi dahulu sebelum melanjutkan perjalanan ke timur. Kami sepakat berhenti pada sebuah masjid yang terletak di pinggir jalan raya. Belum terlalu jauh dari pelabuhan Lembar. Masjid itu tidak terlalu besar. Berhiaskan arsitektur timur tengah yang kental. Di Lombok, bagi mereka yang beriman, tidak perlu takut ketinggalanwaktu sholat dalam perjalanan. Tempat peribadatan seperti masjid dan surausurau ada di sepanjang jalan dengan jarak yang tidak terlalu jauh. Warga setiap desa di sepanjang jalan utama, pasti membangun masjid. Bahkan di desa-desa terpencil sekalipun, tempat ibadah tidak sukar ditemukan. Tempat ibadah laksana jamur di musim penghujan. Itu sebabnya sribu masjid adalah identitas manis untuk pulauku yang subur ini. (Eva Nourma, 2011: 33-34)

Kehidupan religius yang kental dalam kehidupan masyarakat Sasak dimulai sejak usia dini. Para orang tua di masyarakat Sasak pada saat anak-anak mereka telah berusia di antara enam sampai delapan tahun, anak-anak suku Sasak mulai dimasukkan mengaji. Mengaji di sini, yakni belajar membaca dan memahami Al Qur'an yang merupakan kita suci umat Islam dan belajar tentang syariat yang diajarkan. Sebagaimana kutipan berikut.

Seperti yang sering aku dengar dari guru ngaji dengan kopiah lusuh di surau pinggir desa 
Perigi. Guru ngaji yang dekat dengan Tuhan itu pun miskin. Ah, Lombok. Apalagi orang Sasak yang tidak pernah mengaji. (Eva Nourma, 2011: 45)

Kutipan di atas menggambarkan nilai religus yang diterapkan oleh para tokoh dalam novel Sri Rinjani. Ibadah sholat yang dilakukan oleh para tokoh sebagai wujud syukur dan penghambaan diri kepada Allah Swt. atas nikmat dan anugerah yang diberikan. Hal tersebut menandakan nilai pendidikan agama yang patut diteladani bagi penikamat karya sastra terutama bagi generasi muda.

Nilai pendidikan agama tidak terbatas hanya dengan ibadah sholat saja melainkan dapat berupa aktifitas-aktifitas yang memang diberikan tuntunan oleh Allah Swt. dan Rasulullah saw. Salah satu tuntunan yang diajarkan yakni mengaji atau membaca kitab suci Al Qur'an yang merupakan wayu yang dijadikan pedoman atau pegangan hidup bagi umat Islam di seluruh dunia.

\section{b. Nilai Pendidikan Sosial}

Kehidupan sosial yang digambarkan dalam novel Sri Rinjani memperlihatkan kehidupan masyarakat pedesaaan. Nilai pendidikan sosial dalam novel Sri Rinjani ditunjukkan oleh tokoh Pak Kamil adalah memberikan bantuan bagi masyarakat yang membutuhkan di desa Perigi. Hal tersebut dapat dilihat dalam kutipan berikut.

Hatiku berdesir mendengar kabar dari orang yang paling kaya di desa Perigi itu.Pak Kamil sangat disegani oleh masyarakat desa ku. Selain sering membantu sesama warga yang membutuhkan, Pak Kamil juga teman akrab ayah semenjak mereka masih duduk di sekolah dasar dahulu. Kalau tidak ada bantuan dari Pak Kamil, rasanya ayah tidak akan sampai ke negeri seberang... (Eva Nourma, 2011: 70)

Sikap peduli sosial yang ditampakkan oleh tokoh dalam novel Sri Rinjani bukan hanya itu saja, melainkan saling tolong menolong ketika ia memiliki kelebihan dari kebanyakan orang tanpa meminta pamrih. Hal itu dapat dilihat dari kutipan berikut.

Kakek pun tumbuh menjadi seorang tokoh masyarakat. Ia sangat dihormati karena kemampuannya membaca tanda-tanda alam yang tersembunyi. Bacaan tanda yang sangat sempurna. Kakek juga mampu menentukan kapan hari baik untuk menggelar upacara adat. Bahkan hampir semua warga ditentukan hari pernikahannya oleh kakek. Ketaatannya menjalankan agama membuat wajah kakek seperti memamntulkan cahaya. Ia menguasai bahasa Selaparang yang sudah pada masa itu. Itulah sebabnya, ia banyak diminta warga membacakan kitab-kitab lontar yang diyakini sisa-sisa peninggalan kerajaan Selaparang yang mampu diselamatkan. Ketokohannyalah yang membuat kakek sering diundang oleh bangsawan Sumbawa sekadar untuk diminta bercerita tentang hubungan Lombok dengan Sumbawa di masa silam. Hubungan persaudaraan yang erat. (Eva Nourma, 2011:13)

\section{c. Nilai Pendidikan Adat/ Budaya}

Inti dari kebudayaan adalah sistem nilai budaya. Sistem nilai budaya akan mempengaruhi dan menata semua elemen yang terdapat pada struktur kehidupan manusia. Sistem nilai budaya terdiri dari konsep-konsepsi yang hidup dalam alam pikiran warga masyarakat, mengenai segala sesuatu yang dianggap amat bernilai dan sakral dalam hidup. Oleh sebab itu, sistem nilai budaya merupakan pedoman tertinggi bagi masyarakat selain nilai agama dan hukum pemerintah. Nilai budaya yang terdapat dalam novel Sri Rinjani berupa kebiasaan yang dilakukan oleh masyarakat Lombok dalam tradisi bau nyale (menangkap cacing laut). Nilai pendidikan yang dapat diambil dari tradisi bau nyale adalah kebersamaan yang dibalut dalam bingkai budaya lokal. Sebagaimana terdapat dalam kutipan di bawah ini.

Pertemuan indah ketika mereka mengunjungi pesta bau nyale di pantai Kaliantan. Pesta rakyat yang mampu mengumpulkan ribuan manusia dari belahan Lombok. Terutama suku Sasak sangat identik dengan pestame rakyat itu. (Eva Nourma, 2011: 8)

Nilai pendidikan budaya yang ditampilkan juga dalam novel Sri Rinjani adalah budaya saling menghormati. Saling menghormati tidak memandang status dan golongan. Sebagaiman yang ditujukkan oleh tokoh Pak Kamil yang menghormati tamu 
dengan meminta izin untuk menemui tokoh aku yang juga adalah tamunya. Berikut kutipannya.

Pak Kamil terlihat sedang menjamu tamu di berugak bertiang enam. Berugak itu tampak kokoh. Bangunan tradisional Sasak itu terbuat dari kayu kelas tinggi. Sesuai dengan kemampuan empunya. Melihat kedatanganku pak Kamil langsung meminta izin kepada tamunya untuk menghentikan pembicaraan sebentar. (Eva Nourma, 2011: 78)

\section{Relevansi Novel Sri Rinjani Karya Eva Nourma dalam Pembelajaran Sastra Pembelajaran sastra}

Tentunya sudah sampai pada tahap anlisis karya sastra. Peserta didik tidak hanya diajarkan untuk lebih mengenal karya sastra, tetapi juga mampu memahami isi agar tumbuh pemahaman dan menghargai cipta sastra sebagai suatu karya yang indah dan bermakna. Tujuan pembelajaran sastra di sekolah agar peserta didik tidak hanya mengerti dam memahami isi karya sastra saja, tetapi juga mengambil pejaran yang digambarkan oleh para tokoh. Hal ini senada dengan pendapat Nurgiyantoro (2013: 322) bahwa di dalam sebuah karya sastra melalui cerita, sikap, dan tingkah laku tokoh-tokoh, pembaca diharapkan dapat mengambil hikmah dari pesan yang disampaikan. Pembelajaran sastra idealnya dapat memberikan andil yang signifikan terhadap keberhasilan pengembangan manusia yang diinginkan, guna mendapatkan hasil yang baik dapat dilasanakan dengan pendekatan yang tepat.

Salah satu pembelajaran sastra di Sekolah Menengah Atas adalah tentang ekstrinsik novel. Pembelajaran sastra diyakini mampu seabgai salah satu sarana untuk menanam, memupuk, mengembangkan, dan melestarikan nilai-nilai yang baik (Nurgiyantoro, 2013: 35). Pembelajaran yang berkaitan dengan unsur ekstrinsik novel terdapat dalam kompetensi dasar kelas XII semester II Kurikulum 2013 Kompetensi Dasar 4.1 yang berbunyi menginterpretasikan makna teks cerita fiksi dalam novel baik secara lisan maupun tulisan.

Novel Sri Rinjani karya Eva Nourma adalah salah satu novel edukasi yang mengandung nilai pendidikan, sehingga dapat dijadikan penunjang pembelajaran sastra di Sekolah Menengah Atas. Hal ini diungkapkan oleh Bukhori Muslim,
M.Pd. salah satu guru di Madrasah Aliyah Negeri Selong.

"Jika dilihat dari kacamata pendidikan, tentu novel ini tergolong novel yang ersifat mendidik dan baik dibaca oleh kalangan pelajar dan mahasiswa. Sedangkan jika dikaitkan denga pembelajaran sastra di SMA/MA tentu juga layak dan pantas digunakan dalam pembelajaran sastra di SMA/MA." (CLHW, 2019)

Selain mengandung nilai pendidikan, novel Sri Rinjani yang mengangkat sosial budaya masyarakat Sasak jika diterapkan dalam pembelajaran sastra di SMA khususnya di pulau Lombok akan lebih cepat diserap karena berada dekat dengan peserta didik. Peserta didik akan merasa lebih intim ketika belajar dengan menggunakan novel yang mengangkat lokalitas daerah mereka. Sebagaimana dinyatakan oleh Syamsul Rahman, S.Pd. salah satu guru di Madrasah Aliyah Negeri Selong.

"Sebagai penikmat karya sastra dan tanpa ada rasa subjektifitas, saya menilai novel Sri Rinjani adalah novel yang kritis yang baik. Novel ini perlu atau direkomendasikan untuk dibaca oleh kalangan pelajar dan mahasiswa dikarenakan nilai-nilai yang terkandung di dalam novel tersebut sangat bermanfaat bagi pelajar dan mahasiswa untuk meningkatkan motivasi untuk terus belajar dan belajar. Selain itu, novel ini berlatar belakang sosial masyarakat Sasak yang sangat dekat dengan pembaca dari kalangan pelajar dan mahasiswa Sasak akan semakin meberikan pengetahuan dan wawasan tentang kehidupan masyarakat Sasak yang terdapat di desa Selayar dan Perigi." (CLHW, 2019)

\section{SIMPULAN}

Nilai pendidikan yang terdapat dalam novel Sri Rinjani karya Eva Nourma, yakni nilai pendidikan agama (religius) yang berupa ketekunan melaksanakan ibadah sholat, nilai pendidikan sosial berupa sikap peduli terhadap sesama dan saling membantu satu sama lain, nilai pendidikan karakter yang terdiri dari nilai religius, kerja keras, peduli sosial, dan tanggung jawab. Nilai pendidikan adat/budaya berupa kebiasaan yang dilakukan oleh masyarakat sejak dahulu hingga sekarang, yaitu tradisi 
BauNyale dan membuat bangunan tradisional Sasak Berugak.

Relevansinya dengan pembelajaran sastra adalah siswa dapat mengambil pelajaran dalam novel Sri Rinjani karena cerita yang diangkat dekat dengan lingkungan siswa dan memiliki nilai-nilai positif serta dapat melestarikan adat/budaya suku Sasak.

\section{DAFTAR PUSTAKA}

Moleong, L.J. 2008. Metodologi Penelitian Kualitatif. Bandung: Remaja Rosdakarya Bandung

Nurgiyantoro, B. 2010.Teori Pengkajian Fiksi. Yogyakarta: Gajah Mada University Press

Nourma, E. 2011.Sri Rinjani. Pancor: STKIP Hamzanwadi Press

Segers, R. T. 2000. Evaluasi Teks Sastra. Diterjemahkan oleh Suminto A. Sayuti. Yogyakarta: AdiCita

Sugiono. 2012. Metode Penelitian Kuantitatif Kualitatif dan R\&D. Bandung: Alfabeta

Wawancara dengan Bukhori Muslim, M.Pd guru Bahasa Indonesia MAN 1 Lotim pada tanggal 20 November 2019

Wawancara dengan Syamsul Rahman, S.Pd guru Bahasa Indonesia MAN 1 Lotim pada tanggal 20 November 2019

Wellek, R.\& Warren, A. 2014. Teori Kesusastraan. Diterjemahkan oleh Melani Budianta.Jakarta: Gramedia 